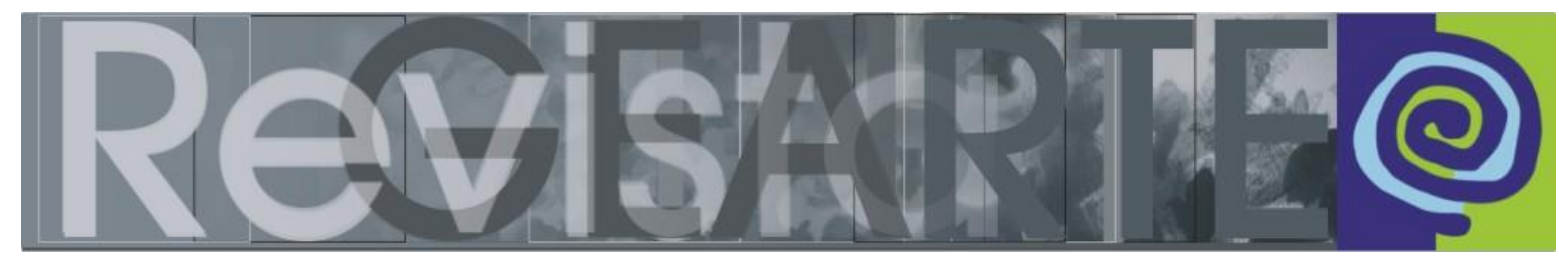

Volume 1, Número 1, Abril/2014, ISSN 2357-9854

\title{
Submergir-se: incorporar espaços (in)habitáveis
}

\author{
Teresa Torres Eça (UP - Portugal)
}

\begin{abstract}
RESUMO
Este texto relata alguns projetos de investigação colaborativa nos quais se trabalhou mais a partir de conceitos do que de métodos. Partimos da questão de espaços de fronteira, entre-lugares onde a arte educação pode invocar a sua hibridez. Descrevemos estratégias da performance artística como pedagogia em espaços de construção colaborativa de aprendizagem para invocar atitudes que possam levar à provocação da visibilidade de uma arte educação comprometida com o mundo real. Falaremos de ações desenvolvidas com vários professores, em contextos de educação formal e não formal, no Brasil e em Portugal e da necessidade de trabalhar em rede e de utilizar as potencialidades que as tecnologias da comunicação oferecem.
\end{abstract}

PALAVRAS-CHAVE:

investigação-colaborativa; arte educação; ativismo; educação expandida

\section{ABSTRACT}

This paper reports some collaborative research projects that were based more on concepts than on methods. The starting point was the question of boundary places, the in-between places where art education can call on its hybridity. We describe strategies of artistic performance, as the pedagogy in places of collaborative construction of learning, in order to call on attitudes that may lead to provocation of visibility of an art education committed to the real world. We will talk about actions developed with a number of teachers, in contexts of formal and non-formal education, in Brazil and in Portugal, the need to work in network and to use the potential that technologies of communication offer.

\section{KEYWORDS}

collaborative research; art education; activism; expanded education

\section{(Des)habitamos espaços porque não cabemos nas portas}

Escrevo este artigo na terceira pessoa porque acredito que o trabalho que faço, as ideias e as estratégias que experimento são fruto da minha aprendizagem em redes. Carrego na minha fala não só as referências dos livros e artigos que li sobre arte educação, mas também o que aprendi com os outros, nos projetos que realizei com educadores e nas conversas com amigos. Como investigadora integro o Grupo de Investigação em Arte Educação C3 impulsionador da Plataforma de Projetos Educativos Inter-Ação. Situo a minha prática presente nas ideias que esse grupo C3 tem, vindo a lançar vírus contagiantes que pretendem infectar a arte educação com a necessidade de provocar situações de compromisso político e social. 


\section{Percorremos espaços (in)habitáveis porque só aí podemos completamente realizar o nosso trabalho}

Os espaços habitáveis são extremamente ambíguos, entre a realidade física, a realidade virtual e a realidade expandida. Integramo-nos com o nosso corpo físico e com representações do nosso corpo em ambientes de comunicação diversa. Os pressupostos geográficos têm hoje escalas translocais e tempos ubíquos. Movemonos rapidamente entre locais e entre grupos de variados interesses. As culturas e as artes são híbridas e, mesmo apesar dos esforços das instituições de poder e das elites intelectuais para manter distâncias, a capilaridade é constante. Vivemos espaços de entropia onde o imprevisível e o surpreendente acontecem. Espaços de comércio e espaços de partilha. Os museus e as galerias deixaram de ser os indicadores dos lugares da arte, a experiência artística acontece em qualquer lugar. Rejeitamos os princípios universalistas das perguntas modernistas do tipo "O que é a arte?" E duvidamos do significado vazio da pergunta "Quando é arte?" Experimentamos a arte nas mais variadas circunstâncias, sendo uma delas a educação.

A experiência artística deixou de se poder definir por conceitos elitistas de apreciação ou fruição; passamos a acreditar que seria uma vivência relacional ativa, onde vários intervenientes partilham um fenômeno visual, a partir de diferentes interpretações influenciadas por histórias de vida particulares (ROGOFF, 2000). Preocupamo-nos com a sobrevivência de direitos autorais, mas acreditamos em conteúdos abertos e na possibilidade da cultura livre.

Reconhecemos a importância da educação para a compreensão da cultura visual e acreditamos que, como educadores, deveremos ajudar os estudantes a desenvolver a literacia multimidiática. Mas queremos ir mais além, mais além das nossas histórias de vida, mais além dos nossos pressupostos ocidentais que tendem a separar as várias áreas das artes e entrar no mundo multimidiático, no qual as pessoas vivem processos imersivos através do som, da imagem e do corpo. Gostaríamos de habitar esses espaços, que os mecanismos educacionais tendem a desagregar. Nos interstícios encontramos um processo artístico sem idade, ou com a idade da humanidade, nos quais a arte e a educação se mesclam. Pela performance celebramos processos de aprendizagem grupal. Envolvemo-nos totalmente com o compromisso do nosso corpo que se expõe como elemento de um grupo numa 
comunhão sem retorno. Para nós, trabalhar em arte educação, qualquer que seja o grau de ensino, implica corporizar a aprendizagem num ritual de grupo, tal como numa dança circular. A performance artística como pedagogia representa um espaço criativo e intelectual através do qual os estudantes podem aprender a expor, examinar e criticar paradigmas culturais a partir das suas diferentes perspectivas vivenciais. A conjunção de conteúdos acadêmicos "públicos" com os conteúdos "privados" dos estudantes, que ocorre através da incorporação do discurso e da prática da performance artística, transforma a sala de aula num espaço contencioso onde discursos hegemônicos podem ser desafiados a partir das perspectivas das memórias pessoais dos estudantes e das suas histórias pessoais (GAROIAN, 2002, p. 18-24).

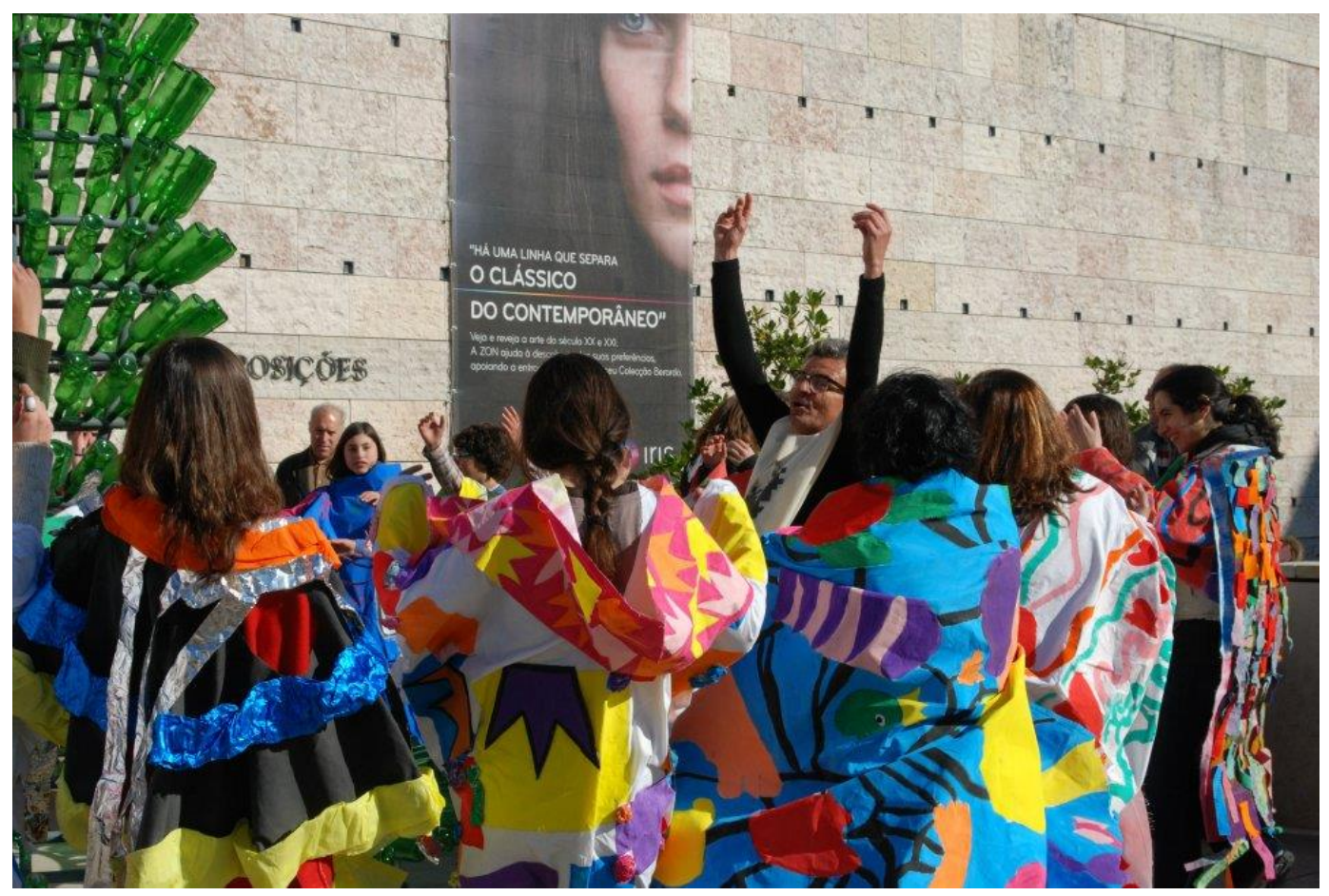

Figura 1: Alunos e professoras numa performance do projeto Comparangoleiros. Entrada do Museu Berardo, Lisboa, Fevereiro de 2012. Foto Isabel Trindade.

Pensamos a arte na educação e a educação na arte. Percorremos espaços de educação com artes e educação pelas artes. Atravessamos pontes entre as várias disciplinas que convocamos em cada ação educativa através das artes. Tecemos redes quando não existem pontes entre as disciplinas e escondemo-nos nas margens porque não estamos no centro do conhecimento dito mais útil. $E$, dessas margens periféricas, onde se faz arte educação, fazemos o centro das nossas vidas. Trabalhamos em equipes multidisciplinares. 
Com o grupo Comparangoleiros partimos da ideia da performance "Parangolés", de Helio Oiticica, para um trabalho com alunos sobre arte contemporânea. Acabamos por criar uma rede enorme de alunos e professores que vestiram a pele da mudança. Sentiram o poder do Parangolé, como ferramenta performática, capaz de criar relações afetivas com os outros, de provocar situações de diálogo tanto nos professores como nos alunos. Nesses projetos, ao arriscar trabalhar nas margens, entre os lugares da cidadania, da história, da geografia, do ambiente, das artes visuais, das artes performáticas, corremos riscos de perder o rigor e o controle. Os conhecimentos específicos das disciplinas só são convocados caso necessário. No entanto, tal risco é compensador pelos ganhos no crescimento da pessoa. E, não será o conhecimento necessário o mais útil? O professor não é o único detentor do conhecimento. Mas o conhecimento não é propriedade de ninguém, é algo que se vai construindo em conjunto.

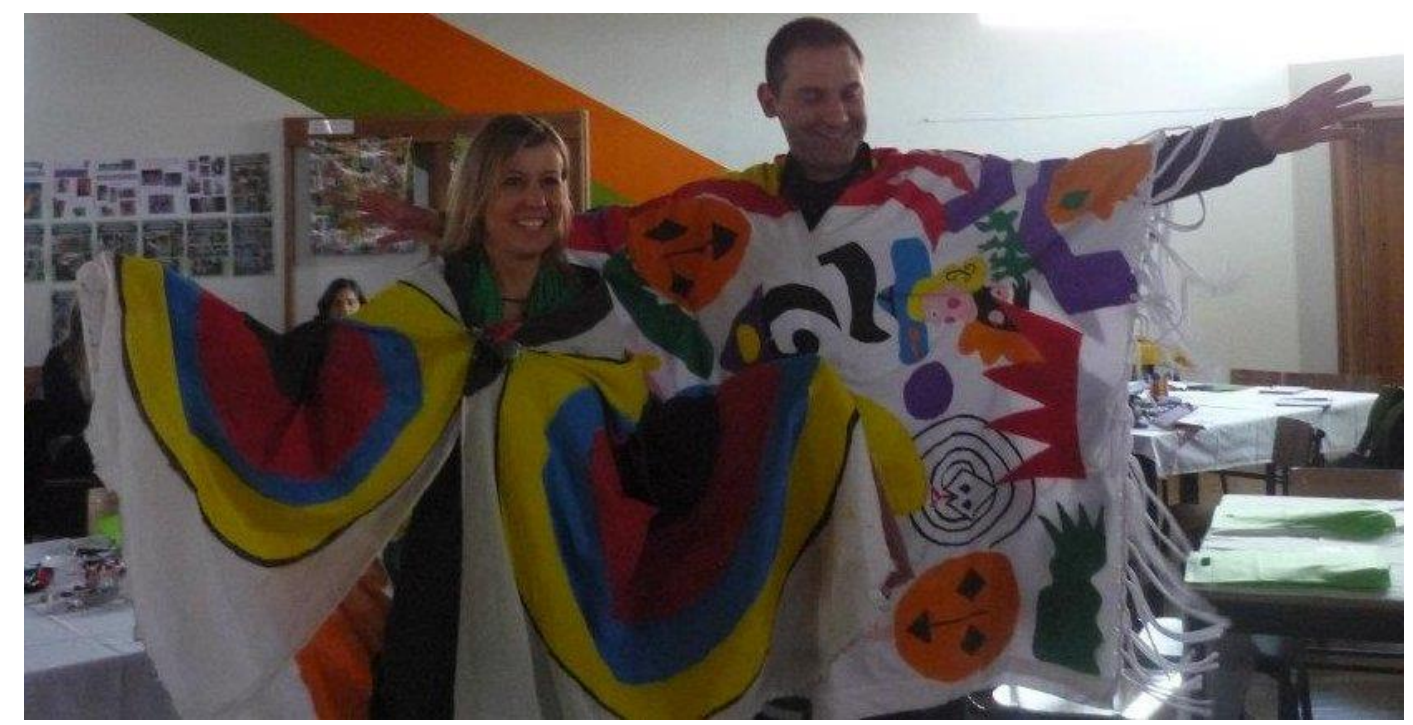

Figura 2: Professores envolvidos no espírito Comparangoleiros durante o 24를 Encontro Anual da APECV, Constância, Maio 2012. Foto da autora.

Ao vestir, cantar e dançar o Parangolé com alunos e professores, sentimo-nos portadores de uma filosofia educativa. A hibridez das artes no ato performático abriu horizontes ilimitados a uma nova maneira de ser professor e de ser aluno. Fez-nos sentir parte de um ritual de alegria e de colaboração, ritual completamente diferente dos rituais competitivo/punitivo que as escolas favorecem. Compreendemo-nos como professores, com as nossas histórias, os nossos receios e as nossas limitações. Refletimos diariamente as nossas escolhas. O Parangolé é a metáfora dessa reflexão; 
no Parangolé pintamos, colamos, desenhamos as nossas memórias e com elas construímos memórias de eventos coletivos. Incorporamos sonhos, sentimentos, afetos e ações. Partimos da história de cada um, ouvindo os estudantes e fazemos com eles mapas de descobrimento de si e dos outros, envolvemo-os em procuras com questões difíceis, temas problemáticos trazidos por eles ou por nós; subimos o nível sempre que possível para ajudar o grupo a sair do conforto dos estereótipos e das respostas prontas.

Ouvimos o que os nossos colegas têm para partilhar e colaboramos nos seus projetos mais arriscados. Com o professor Ariclaudio, de Diadema (MG-Brasil), e a professora Dace, de Riga (Letônia), em 2011, convidamos os alunos a criarem, a partir do estudo das artes, um objeto protetor. Baseados na mitologia letã das coroas de flores do solstício de verão, os alunos de Dace enviaram mandalas; os alunos brasileiros, baseados na arte contemporânea do Brasil, enviaram objetos-colagem, multimidiático, e os portugueses baseados no artesanato português enviaram azulejos. A partir do tema "Proteção", vários mundos foram descobertos através das artes, mundos pessoais e coletivos. Provocamos situações em que se geram histórias, perguntas, e mais perguntas. Agimos para aprender e ser apreendido. Para amar e ser amados. E aí, reside a nossa maior criação artística.

\section{Incorporamos narrativas}

Nas situações que criamos caminhamos nas bordas da inconformidade e geramos desconforto. Aí reside o nosso desafio educacional. É preciso estar atento, para continuar o exercício da liberdade.

Temos um compromisso urgente com os nossos estudantes. Somos arte educadores, resistentes, resilientes e ativos.

Trabalhamos com os sentidos, a liberdade, a expressão, a comunicação, o pensamento e a vontade. Propomos trabalhos de projeto; ações implicadas sobre temas que relevem compromissos com as comunidades, que provoquem desconforto e impulsionem debates. Por exemplo, na ação "Sorria" convidamos professores e alunos de várias escolas para, na sua escola ou na praça central da sua cidade, oferecer um desenho aos passantes. O desenho dizia "sorria", porque o mundo está cheio de tristeza. Os alunos, na rua, às vezes eram rejeitados pelos passantes; foi 
cruel, às vezes; outras vezes eram abraçados. Foi uma experiência que nunca esquecerão. É preciso sair da segurança dos muros da escola; a escola pode ser em qualquer lugar.

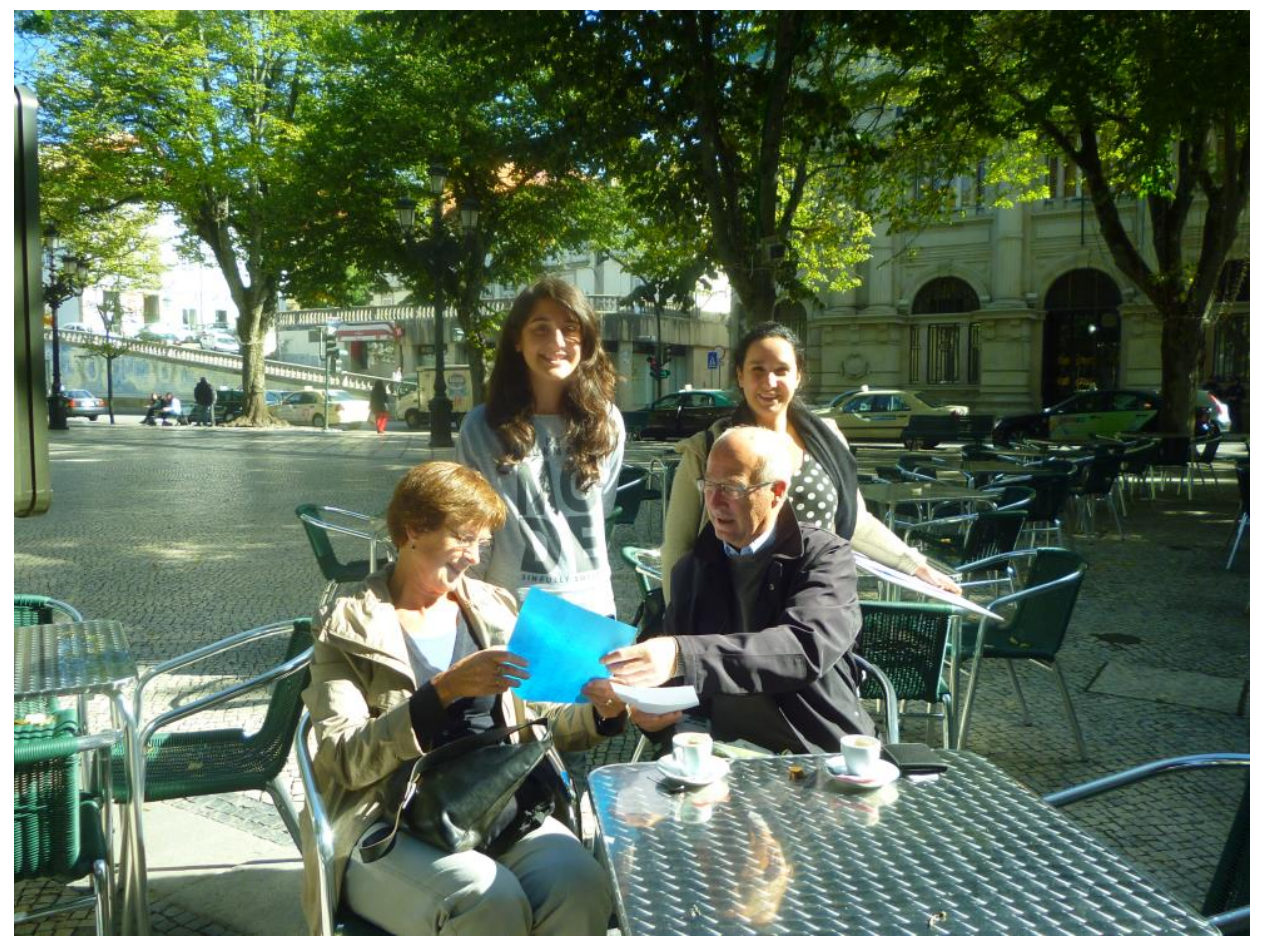

Figura 3: Ação de Rua: Sorria, APECV/Movimento desenho 12, Outubro 2012. Foto da autora

$\mathrm{Na}$ oficina de intervenção comunitária, coordenada pela artista Ângela Saldanha, "Na Companha", ela propôs aos moradores do bairro piscatório de Espinho um painel coletivo. Trouxe o desenho e a dança como festa para o bairro, o desenho para contar as suas vidas, a faina do mar, a espera, a venda do peixe, as pequenas alegrias que fazem parte da vida do bairro. Na ação "Mais que Nunca", levada a cabo durante a Semana Internacional da Educação Artística com o grupo C3, distribuímos centenas de cartazes em todo o mundo sobre a importância da educação artística. Cartazes que integravam palavras-chave elaboradas por arte educadores em rede e uma colagem, que o pintor Xesus Carballido elaborou especialmente para a ação. São ações curtas ou longas com eventos visíveis na rua, no bairro e que acabam sempre por ir parar nos grupos sociais da Internet (Facebook; Youtube; Tweeter). Convidamos alunos e professores a clicar em "curtir"; usamos celulares, cartões, balões, qualquer meio para exprimir e comunicar. Fazemo-nos visíveis. 


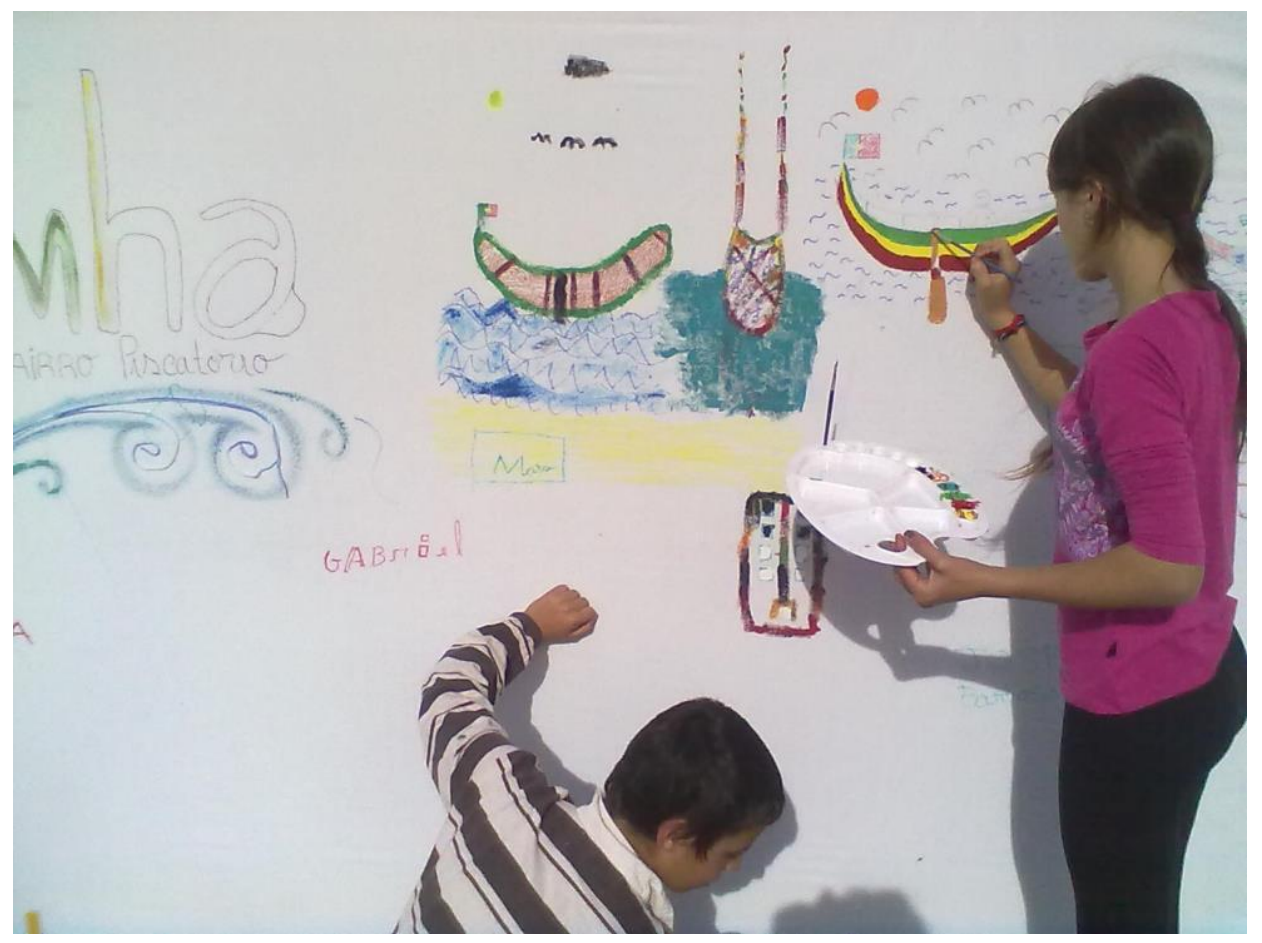

Figura 4: Oficina Comunitária de Angela Saldanha com moradores do Bairro piscatório de Espinho: na Companha, Dezembro 2012. Foto da autora.

Trabalhamos com os sentidos a liberdade, a expressão, a comunicação, o pensamento e a vontade.

Trabalhamos com alunos que não são mais puros receptores; consumidores de cultura, mas que se transformaram em "prosumidores" (DUNCUM, 2010) no sentido de recicladores de cultura; criadores de novos objetos culturais a partir da oferta global da cultura da mídia. Muitas vezes os professores de artes visuais perguntam qual será o seu papel, como poderão ser mais ativos e úteis. Os nossos estudantes, há muito deixaram de ser objetos passivos de aprendizagem para se tornarem sujeitos em construção contínua. Embora a maior parte desse processo de construção passe pelo lado de fora da escola. As crianças e os jovens são indivíduos que desenvolveram capacidades muito interessantes, conseguem receber informação em diferentes formatos e de variadas fontes ao mesmo tempo. Mas, na escola têm cada vez mais dificuldades de concentração e desmotivam-se. Apenas os muito competitivos, com maior atência para as tarefas lógico-linguísticas, sobrevivem confortavelmente. Os mais criativos são os que mais sofrem nos sistemas escolares. Marta, estudante de Bioquímica, estuda nos manuais on-line da universidade numa janela do écran do computador, enquanto vê um filme noutra janela, copia outro filme 
noutra janela para a irmã, ouve um áudio livro no MP3 e faz um desenho num papel, tudo ao mesmo tempo. Isso é o que normalmente os bons estudantes fazem. Catarina, estudante do ensino médio, também é muito criativa, mas mais inconformista e menos estudiosa, usa o computador de um modo um pouco diferente, mais virada para as redes sociais, Skype e jogos on-line. Eles são incríveis! Como conseguem prestar atenção a tanta coisa ao mesmo tempo? Recebem milhões de bytes por segundo, a velocidades vertiginosas, comunicam-se com outras pessoas, para mim misteriosas, usando fotos, vídeos, texto e palavra que elas produzem a partir do que encontram. No mundo deles tudo é música, imagem e movimento. É um mundo fabuloso, cheio de possibilidades de conhecimento e de conexão com outros!

Todas essas potencialidades que se abriram com a banalização do cibermundo são desafios para a educação. Nunca foi tão fácil aceder, contatar, comunicar! Nunca foi tão fácil produzir e publicar conteúdos! Essa facilidade inunda-nos de informação absurda, de contatos insignificantes e de comunicação irrelevantes. De excesso! De caos? Uma lixeira grandiosa à escala global. Mas não existirão mais de mil maneiras de catar no lixo. Talvez tenhamos apenas que voltar a pensar o que é verdadeiramente importante para nós educadores numa sociedade com essas possibilidades. Pensar de novo o ser, o estar e o ter.

Repensar o termo "Acesso". Quanto custa o acesso à informação? Quem lucra com os conteúdos fechados? Quem está no mercado da informação? Qual o papel dos emissores (criadores)? Qual o papel das empresas? O papel dos receptoresemissores (prosumidores)? Poderemos mudar as regras da lei da compra utilizando o conceito de partilha da cultura livre (LESSIG, 2004), como usamos os conteúdos abertos?

Queremos ser pessoas livres, estar atentos; ter livre arbítrio. Às vezes, os alunos nos surpreendem. Depois de um projeto cujo tema era a violência contra as mulheres, um grupo de alunos grafitou, no mercado central, a mensagem "sem mulheres não há paz". No início do projeto, a turma declarou que o tema não the interessava; isso não existia, diziam eles, na sua comunidade. Depois de alguma conversa e de muita pesquisa na Internet, em páginas com conteúdos abertos de organizações ligadas aos direitos humanos, acabaram por descobrir que existia um 
pouco por todo o mundo, com muita frequência no país onde viviam, e até na sua comunidade.

\section{Cibercultura: Precisamos navegar}

A educação é comunicação, a comunicação no século XXI produz-se, partilhase e distribui-se, como já vimos, cada vez mais, por meios digitalizados (SAURA, 2011). A digitalização permitiu uma sociedade de verdadeira democratização e transformação social na medida em que permitiu baixar custo do transporte da informação. Não só em termos de recepção como também de emissão, isso faz com que seja possível trabalhar em redes sem grandes custos, favorecendo a inteligência coletiva, um conceito que tem vindo a ser desenvolvido na área das ciências e das tecnologias pelos estudiosos dos sistemas complexos. Se, nesse tipo de sociedade, queremos ser críticos, compreender e transformar a realidade, não podemos descurar a vertente da inteligência coletiva e dos meios tecnológicos na qual ela se cultiva. É necessário habitar a ambiguidade dos espaços reais e virtuais em que nos movemos, e as tecnologias que usamos sem demasiadas expectativas. As tecnologias são apenas tecnologias. Os meios não libertam, o que pode libertar (ou alienar) é o modo como os utilizamos. Precisamos navegar, utilizando a metáfora do ciberespaço, porque grande parte da cultura passa por narrativas transmidiáticas, transmitida por diferentes linguagens (verbais, icônicas, etc.) e expandidas por meios diversificados (cinema, literatura, televisão, videojogos, blogs, wikis, etc). Essa dispersão é uma das mais importantes fontes de complexidade da cultura popular contemporânea. Precisamos trabalhar também com essa dispersão.

\section{Precisamos afundar-nos}

Vivemos inquirindo. Somos profissionais que refletem a partir das suas experiências para gerar conhecimentos mais profundos. Somos espelhos ajudando outros a refletir a partir das suas experiências. Somos redes onde as reflexões se partilham. Usamos processos metafóricos, exageramos, repetimos até à exaustão, transformamos e criamos. Usamos as imagens como ponto de partida para a reflexão sobre a construção das nossas experiências. Afundamo-nos na procura do Eu e do Outro usando processos holísticos não verbais, precisamos tornar o nosso trabalho visível. 


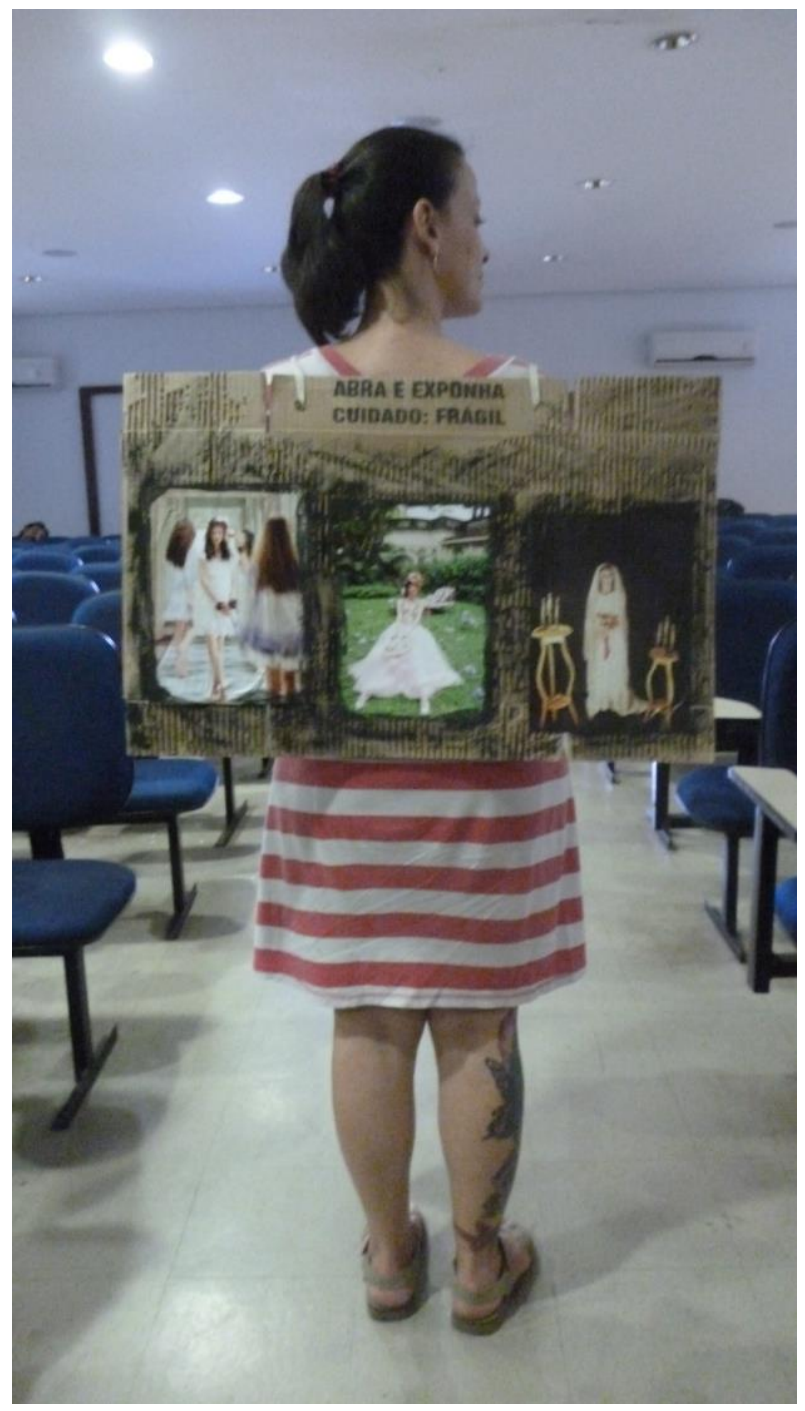

Figura 5: Kerly mostrando o seu cartaz de vestir realizado na Oficina de artes plásticas para professores, Goiânia, Goiás, Brasil, Dez. 2012. Foto da autora.

Muitas vezes é difícil arranjar espaços de exposição gratuitos; existem muito poucos espaços abertos ao cidadão comum. A publicidade é um negócio duro e as leis promovem os negócios. Por seu lado, os museus e as galerias só promovem as imagens que interessam aos seus negócios. Raramente se interessam por trabalhos feitos em escolas ou por trabalhos de professores (HUERTA, 2010, p. 39). Então, fica difícil expor publicamente, dar a conhecer ideias, trabalhos, tornar-se visível. Isso foi sentido por pessoas como Ángeles Saura, do grupo @:educación artística en clave 3.0, quando organizou a exposição AVATARES (SAURA, 2012). Foi uma pequena exposição com avatares de professores da península Ibérica e da América Latina que, para além do seu espaço na Internet, ocorreu fisicamente em muitas cidades. Houve 
uma cidade onde a exposição se fez na rua, Ángeles pendurava os avatares nas paredes das casas ou os colocava no chão; durou apenas o tempo de disparar a máquina fotográfica, porque é proibido expor nas ruas sem autorização. Ángeles nessa altura tinha comentado conosco que daquela maneira até se poderia expor nos grandes museus. Bastava haver um portador para carregar com a obra.

Essa ideia pareceu-nos fantástica! Banksy, artista urbano, já tinha procurado profanar o espaço sagrado dos museus em algumas das suas intervenções introduzindo sorrateiramente artefatos nas paredes de salas de exposição de museus; nós acreditávamos que isso era uma proposta muito interessante para se debater em educação. E daí, surgiu o conceito para uma série de oficinas de arte educação ativista. Desafiar os espaços sagrados de exposição/comunicação, dar voz aos professores e alunos, tornar visíveis na comunidade os resultados dos projetos de arte educação. Fazendo cartazes-sanduíche, um dos formatos expositivos mais simples e versáteis que existem na história da publicidade. Essas oficinas tinham um caráter colaborativo, na sequência do que o grupo C3 tinha vindo a desenvolver com a ação "Submergir-se". Submergir-se partia de imagens e de três questões para provocar a reflexão sobre um tema com os participantes utilizando meios de debate não apenas escritos. Uma dessas ações foi realizada no Seminário Atravessar Pontes entre Escolas e Museus realizado pela APECV, no Museu de Serralves (Porto - Portugal), em outubro de 2012. As respostas dos participantes do Porto foram levadas para uma ação similar realizada no LABORarte, na Universidade de Campinas, Campinas Brasil, em 12 de dezembro de 2012. A oficina de Campinas ofereceu um espaço de debate muito rico e terminou com um ritual lindíssimo. Tinha sido proposto fazer uma ciranda aos participantes que ficaram até o final da sessão. Uma das participantes, professora de dança, convidou o grupo a fazer uma dança circular às $18 \mathrm{~h}$. Por acaso, nesse dia 12/12/2012, pessoas de várias partes do Brasil e também de outros países participaram de rodas de Dança Circular Sagrada. A dança do sol, de Bernhard Wosien, com a música Cantata de Bach foi dançada a cada 2 horas, entre 14 e 22 horas, com o intuito de vibrar harmonia, força e amor para a humanidade e para 0 planeta. 
Ao trabalharmos com grupos, se usarmos processos dialógicos, muitas vezes acontecem situações como essa, por serendipitude ${ }^{1}$ o projeto adapta-se e enriquecese com o que cada um dos elementos do grupo pode trazer de novo.

Outra dessas oficinas, realizada também no Brasil, em Goiânia, durante o Congresso ENECIM; V EGEM; IX SENARTE, promovido pela Ciranda da Arte e UFG em dezembro de 2012, foi assistida por Kerly, professora de artes no estado de Goiás. Era uma oficina na qual se procurou analisar anúncios publicitários para depois os reciclar num cartaz de vestir (homem sanduíche). Kerly procurava talvez ideias novas para a sua prática pedagógica e acabou produzindo um cartaz com cartões velhos e folhas de revista. A sua curiosidade a tinha levado a escolher imagens que representavam mulheres: uma mocinha posando para o espelho com pose de dançarina de ballet, o estereótipo da menina bonitinha cheia de sonhos e expectativas; uma noiva numa pose descomposta à porta da igreja e uma imagem da morte como noiva. Como texto ela escolheu: "Abra e Exponha Cuidado Frágil". Kerly compartilhou a sua história com o grupo, expôs-se como história e como portadora de histórias numa reflexão silenciosa, mas poderosa através das imagens. Ousou ser arte educadora, afundada no processo de reflexão sobre imagens comprometeu-se com um tema que certamente interessaria aos seus alunos.

\section{Precisamos submergir}

Relatamos as nossas análises com as linguagens dos sentidos, escrevemos com o silêncio das imagens; com a sonoridade das melodias; com o corpo em movimento.

Somos redes onde as reflexões se partilham. Ser arte educador é hoje um desafio empolgante, porque, dentro das possibilidades de comunicação que as tecnologias nos oferecem, é possível pensar outros modelos de educação, em que não existem margens nem centro, apenas situações de aprendizagem colaborativas através do rigor da reflexão constante sobre as práticas educativas e o mundo para as quais elas são criadas. É preciso submergir, soltar-se de pressupostos pouco

\footnotetext{
${ }^{1}$ Serendipidade é um anglicismo que se refere às descobertas afortunadas feitas, aparentemente, por acaso.
} 
adaptados ao mundo real, saltar os muros do conforto, ter imaginação, arriscar vestir o Parangolé e trazer rituais de alegria e de festa para a educação, não apenas para desenvolver a livre-expressão, experimentar técnicas, analisar criticamente objetos culturais, mas, também, e sobretudo, como processo axiológico de conhecimento e de construção de discursos críticos e diversificados sobre o mundo.

\section{Referências}

DUNCUM, Paul. Young Prosumers, Visual Culture, and Dialogic Pedagogy. In: OLIVEIRA, Miguel; MILHANO, Sandrina. As Artes na Educação: contextos de aprendizagem promotores de criatividade. Leiria: Folheto, 2010. p.79-92.

GAROIAN, Charles. Performance Artística como Pedagogia de Resistência. Imaginar: Revista da Associação de Professores de Expressão e Comunicação Visual, Porto, v. 39, p.18-24, set. 2002.

HUERTA, Ricard. Maestros y museos: educar desde la invisibilidad. Valencia: PUV, 2010.

LESSIG, Lawrence. Free Culture: how big media uses technology and the law to lock down culture and control creativity. 2004. Disponível em: <http://manybooks.net/titles/lessiglother04free_culture.html>.

ROGOFF, Irit. Terra infirma: geography's visual culture. London: Routledge, 2000.

SAURA, Ángeles. Innovación educativa con TIC en Educación Artística, Plástica y Visual: Líneas de investigación y estudios de casos. Sevilla: Eduforma, 2011. p. 61-69.

SAURA, Ángeles. AVATARS for artistic and technological learning. The International Journal of Arts Education, New York, v.10, n.2, p. 59-74, dec. 2012.

\section{Webgrafia}

APECV. Na Companha: bairro piscatório de Espinho. 2012. Disponível em: <http://www.youtube. com/watch?v=3Phh7naoo2l $>$. Acesso em: 11 de julho de 2013.

APECV. Sorria. Org. alunos da ESAM. Out. 2012. Disponível em: <http://www.youtube. $\mathrm{com} /$ watch? $\mathrm{v}=$ TPMjhbXeXFk\&feature=plcp\&list=PLrJ1Vm-f4lfraEOG9SMuZdcxL05nYTz7F> Acesso em: 11 de julho de 2013.

COMPARANGOLEIROS. Disponível em: <http://www.facebook.com/groups/154454424621866/? ref=ts\&fref=ts $>$. Acesso em: 11 de julho de 2013.

EÇA, Teresa. Ação: Sem mulheres não há Paz. Org. Organizacion de voluntarios europeos Adamastor Viseu. Disponível em:<http://www.youtube.com/watch?v=iqjvOSDhkig>. Acesso em: 11 de julho de 2013.

EXPO AVATARES5. 2012. Disponível em:<http://youtu.be/LdJc5VTA-2Y> Acesso em: 11 de julho de 2013.

EXPOSIÇÃO AVATARES. Disponível em:<http://www.arteweb.ning.com>. Acesso em: 11 de julho de 2013.

INTER-ACTION. Plataforma de investigación en procesos artisticos. Coord. Maria Jésus Agra, Cristina Trigo, Teresa Torres Eça, Carmen Franco Vasquez. Disponível em: <http://www.inter-accion. documenta.cat>. Acesso em: 11 de julho de 2013.

MÁlS QUE NUNCA. Disponível em: <http://www.facebook.com/pages/M\%C3\%A1is-quenunca/326921474048455>. Acesso em: 11 de julho de 2013.

SAURA, Ángele. Catálogo Expo Avatares. Red. de artistas docentes. Disponível em: <http://cort.as/3ZMb>. Acesso em: 11 de julho de 2013. 


\section{Teresa Eça}

Professora e pesquisadora da Universidade do Porto (Portugal), é bacharel em Artes Plásticas pela Escola Superior de Belas Artes do Porto, mestre e doutora em Arte/educação pela Universidade de Surrey Roehampton (UK). É vice-presidente da International Society of Education through Art (InSEA) e presidente da Associação de Professores de Expressão e Comunicação Visual (APECV). Foi secretária do Conselho Europeu Regional da InSEA e representante da Europa no Conselho Mundial da InSEA. É membro fundador da Rede Ibérica de Educação Artística, onde atua como moderadora. Atualmente é sub-editora da Revista International Journal of Education through Art. Tem artigos e livros publicados em diversos países.

E-mail - teresatorreseca@gmail.com

Currículo - http://www.degois.pt/visualizador/curriculum.jsp?key=6449161000484867 